ARTICLE

\title{
Janus electrocatalytic flow-through membrane enables highly selective singlet oxygen production
}

Yumeng Zhao ${ }^{1,2}$, Meng Sun (1) ${ }^{2 \times}$, Xiaoxiong Wang ${ }^{2}$, Chi Wang ${ }^{2,3}$, Dongwei Lu1, Wen Ma², Sebastian A. Kube (10 ${ }^{4}$, Jun $\mathrm{Ma}^{1} \&$ Menachem Elimelech (1) ${ }^{2 凶}$

The importance of singlet oxygen $\left({ }^{1} \mathrm{O}_{2}\right)$ in the environmental and biomedical fields has motivated research for effective ${ }^{1} \mathrm{O}_{2}$ production. Electrocatalytic processes hold great potential for highly-automated and scalable ${ }^{1} \mathrm{O}_{2}$ synthesis, but they are energy- and chemicalintensive. Herein, we present a Janus electrocatalytic membrane realizing ultra-efficient ${ }^{1} \mathrm{O}_{2}$ production ( $6.9 \mathrm{mmol}$ per $\mathrm{m}^{3}$ of permeate) and very low energy consumption (13.3 Wh per $\mathrm{m}^{3}$ of permeate) via a fast, flow-through electro-filtration process without the addition of chemical precursors. We confirm that a superoxide-mediated chain reaction, initiated by electrocatalytic oxygen reduction on the cathodic membrane side and subsequently terminated by $\mathrm{H}_{2} \mathrm{O}_{2}$ oxidation on the anodic membrane side, is crucial for ${ }^{1} \mathrm{O}_{2}$ generation. We further demonstrate that the high ${ }^{1} \mathrm{O}_{2}$ production efficiency is mainly attributable to the enhanced mass and charge transfer imparted by nano- and micro-confinement effects within the porous membrane structure. Our findings highlight a new electro-filtration strategy and an innovative reactive membrane design for synthesizing ${ }^{1} \mathrm{O}_{2}$ for a broad range of potential applications including environmental remediation.

\footnotetext{
${ }^{1}$ State Key Laboratory of Urban Water Resource and Environment, Harbin Institute of Technology, Harbin 150090, China. ${ }^{2}$ Department of Chemical and Environmental Engineering, Yale University, New Haven, CT 06520-8286, USA. ${ }^{3}$ School of Environment, Northeast Normal University, Changchun 130024 China. ${ }^{4}$ Department of Mechanical Engineering and Materials Science, Yale University, New Haven, CT 06511, USA. ${ }^{凶}$ email: meng.sun@yale.edu; menachem.elimelech@yale.edu
} 
T he seminal work by $\mathrm{H}$. Kautsky in 1938 revealed an exciting form of molecular oxygen, singlet oxygen $\left({ }^{1} \mathrm{O}_{2}\right)$, which later has been proven to be pivotal in the chemical and biomedical fields ${ }^{1-3}$. This unique nonradical derivative of oxygen, together with hydroxyl radicals $\left({ }^{\circ} \mathrm{OH}\right)$, is considered the most potent among reactive oxygen species (ROS) ${ }^{4,5}$. Compared with the short-lived and unselective ${ }^{\circ} \mathrm{OH}$ radical, the meta-stable ${ }^{1} \mathrm{O}_{2}$, possessing an unoccupied $\pi^{*}$ orbital, shows high selectivity toward electron-rich substances ${ }^{6,7}$, such as pharmaceuticals ${ }^{8}$, unsaturated biomolecules ${ }^{7,9}$, and microbial pathogens ${ }^{10}$. Consequently, ${ }^{1} \mathrm{O}_{2}$ targeted reactions are applied in diverse fields, including water decontamination ${ }^{10}$, photodynamic cancer therapy $^{11}$, and green organic synthesis ${ }^{12}$.

Greater recognition of the paramount importance of ${ }^{1} \mathrm{O}_{2}$ has motivated research for more effective ${ }^{1} \mathrm{O}_{2}$ production. Current approaches for ${ }^{1} \mathrm{O}_{2}$ production mainly include (i) photosensitization using elaborately designed photosensitizers (e.g., molecular dyes ${ }^{13}$ or quantum nanodots ${ }^{14}$ ) for visible or UVA light adsorption ${ }^{8,15}$ and (ii) enzymatic reactions (e.g., peroxidases $^{16}$ and oxygenases ${ }^{17}$ catalysis) in biological systems, relying on rigorous $\mathrm{pH}$ and temperature conditions of the intracellular environment ${ }^{7,18}$. While both approaches face challenges for industrial scale-up, electrocatalysis (EC), a highly automated and facile technology, could offer more approachable ${ }^{1} \mathrm{O}_{2}$ production pathways ${ }^{19-21}$. Specifically, EC enables the flexible generation of critical ${ }^{1} \mathrm{O}_{2}$ precursors, such as hydrogen peroxide ${ }^{22,23}$ and hypochlorite ${ }^{20,24}$. In addition, as an alternative to photoexcitation or chemiexcitation, EC provides efficient electro-excitation to ${ }^{1} \mathrm{O}_{2}$ precursors, such as cathodic activation of peroxymonosulfate $\mathrm{e}^{21}$ and anodic excitation of ferrocene $e^{25}$.

EC, however, is a much less explored process for ${ }^{1} \mathrm{O}_{2}$ generation compared with photosensitization or enzymatic reactions. Present EC pathways rely on high dosages of precursors, which compromise the environmental sustainability of $\mathrm{EC}^{26,27}$. Further, for effective oxidation of target molecules by the in situ generated ${ }^{1} \mathrm{O}_{2}$, EC currently requires long reaction times (range of hours) and consequently consumes high electric energy ${ }^{20,21}$. Therefore, it is critical to improving EC efficacy by eliminating the use of chemicals, significantly shortening residence time, and enhancing the Faradaic efficiency of the process.

Porous membranes have emerged as ideal electrode substrates to enhance EC performance ${ }^{28,29}$. A variety of membrane-like structures have been proposed, including horizontally stacked lamellar channels ${ }^{30}$ and vertically aligned straight-through pores $^{31}$. These porous substrates spatially confine reactants and electrified active sites at the micrometer- and nanometer-scale. Spatial confinement by membrane pores and channels allows for optimal utilization of electrons by reactants due to minimal diffusion distance and mass transfer enhancement ${ }^{30,32}$, thereby overcoming intensive chemical usage in conventional EC systems. In addition, studies also highlighted the importance of flowthrough configuration of membrane electrodes, which renders electrons to flow parallel to the fluid flow direction, further enhancing the charge transfer rates compared to the conventional flow-by mode (i.e., when the flow direction and electric field direction are perpendiculars) ${ }^{33,34}$. To date, reported electrocatalytic membranes render only half-cell reaction (cathodic reduction or anodic oxidation) within a membrane substrate. In such cases, the electrode redox reactions are not fully utilized. Therefore, exploiting the electrocatalytic flow-through porous membrane configuration incorporating both cathodic reduction and anodic oxidation may offer an innovative strategy for ${ }^{1} \mathrm{O}_{2}$ synthesis, featuring enhanced Faradaic and energy efficiency.

Herein, we conceive a Janus electrocatalytic membrane realizing ultra-efficient ${ }^{1} \mathrm{O}_{2}$ production without the addition of chemical precursors. The Janus membrane (Pd-Pt-CM) features double-sided electrochemically reactive surfaces formed by sputtering palladium $(\mathrm{Pd})$ and platinum $(\mathrm{Pt})$ nanoparticles on the respective sides of a ceramic membrane $(\mathrm{CM})$ substrate. We confirmed the co-existence of ${ }^{1} \mathrm{O}_{2}$ and its precursors, and investigated their spatiotemporal distribution throughout the $\mathrm{Pd}-\mathrm{Pt}-\mathrm{CM}$ during electrocatalytic filtration using the Pd- and Ptsides as cathode and anode, respectively. We then evaluated the efficacy of the in situ generated ${ }^{1} \mathrm{O}_{2}$ for water decontamination using sulfamethoxazole as a model organic molecule in the electrocatalytic filtration process. We further proposed a mechanism for the stepwise electrocatalytic production of ${ }^{1} \mathrm{O}_{2}$ by the Pd-Pt-CM through a set of sequential ROS-mediated redox chain reactions within distinct membrane regions. Overall, our findings demonstrate a new paradigm and electrochemical material platform for ${ }^{1} \mathrm{O}_{2}$ production by using a Janus electrocatalytic flow-through membrane.

\section{Results}

Fabrication and properties of Pd-Pt-CM. Due to their intrinsic electrical insulating properties and large thickness ${ }^{35-37}$, CM can serve as ideal substrates for incorporating both cathodic and anodic electrodes on separate sides of CM. This unique feature allows for sequential electro-redox reactions occurring in different inner-porous $\mathrm{CM}$ regions during electrocatalytic filtration. As illustrated in Fig. 1a, the Pd-Pt-CM was synthesized via confocal magnetron co-sputtering (details in "Methods"). Palladium (Pd) and platinum $(\mathrm{Pt})$ nanoparticles were, respectively, sputtered on the feed- and permeate-side surfaces of the CM $(300 \mathrm{kDa}$, thickness of $2.5 \mathrm{~mm}$ ). Noble metal nanoparticles are chosen as they exhibit high electrical conductivity and render efficient EC reactions with lasting stability 38,39 .

Discernible color transformations for both the $\mathrm{Pd}-\mathrm{CM}$ and Pt-CM surfaces (Supplementary Fig. 1) confirmed the respective metal deposition. Figure 1b, $c$ depicts the morphologies of the $\mathrm{Pd}-\mathrm{Pt}-\mathrm{CM}$ by scanning electron microscopy (SEM) overlapped with the elemental mapping of X-ray EDS. Sputtered Pd and Pt nanoparticles penetrated into the membrane surfaces (detailed EDS mapping results are shown in Supplementary Figs. 2 and 3), exhibiting notable sputtered depths of approximately $60 \mu \mathrm{m}$ (Fig. 1b, orange) and $90 \mu \mathrm{m}$ (Fig. 1c, purple), respectively. Such deep inner-pore sputtering guarantees EC reactions within the confined porous membrane structure, instead of only the membrane surface. The larger sputtered depth of Pt-CM than that of Pd-CM, under the same sputtering thickness, is attributed to the distinct asymmetric porous architecture of the pristine $\mathrm{CM}$ (Supplementary Fig. 4). In addition, Pd and Pt nanoparticles were uniformly deposited on the respective surfaces of the Pd-Pt-CM as shown by the even distribution of the EDS signals of Pd (Fig. 1b inset, orange) and Pt (Fig. 1c inset, purple), suggesting unimpeded electron transfer over the membrane surfaces during EC reactions.

Conductance properties of the Pd-Pt-CM were further quantified by electrochemical impedance spectroscopy (EIS). As illustrated in Fig. 1d, we observed a 6 -fold and 40-fold decrease in the amplitudes of the semicircles for the $\mathrm{Pd}-\mathrm{CM}$ and $\mathrm{Pt}-\mathrm{CM}$ surfaces, respectively, compared to the corresponding sides of the pristine CM. This observation indicates that the sputtering of $\mathrm{Pd}$ and $\mathrm{Pt}$ nanoparticles notably reduces the charge transfer resistance and facilitates electron transfer of the functionalized membrane surfaces ${ }^{40}$. Further, the Pt-CM surface exhibits much lower charge transfer resistance than that of the $\mathrm{Pd}-\mathrm{CM}$ surface, which could be attributed to the synergistic effect of the higher intrinsic conductivity of Pt and the larger sputtered depth.

The elemental composition and the crystalline structure of the $\mathrm{Pd}-\mathrm{Pt}-\mathrm{CM}$ were investigated by $\mathrm{X}$-ray photoelectron 
a

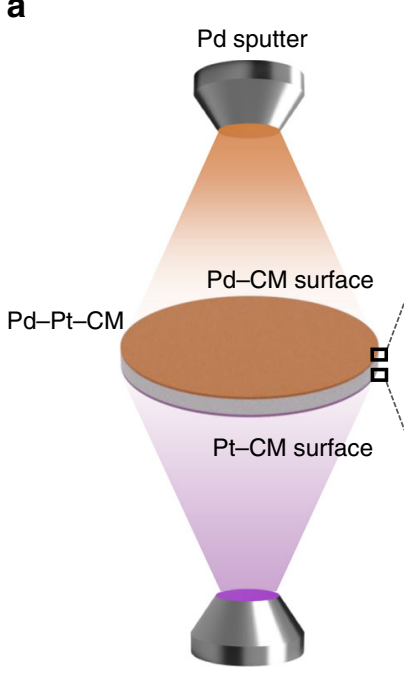

Pt sputter
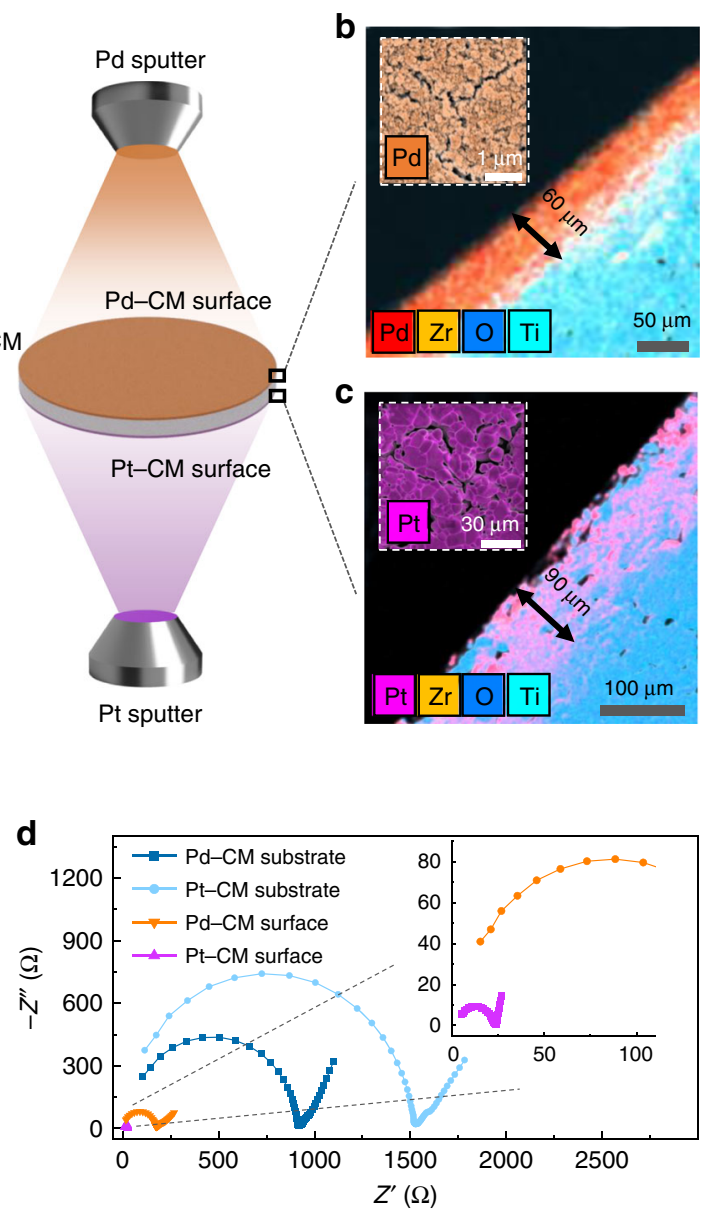
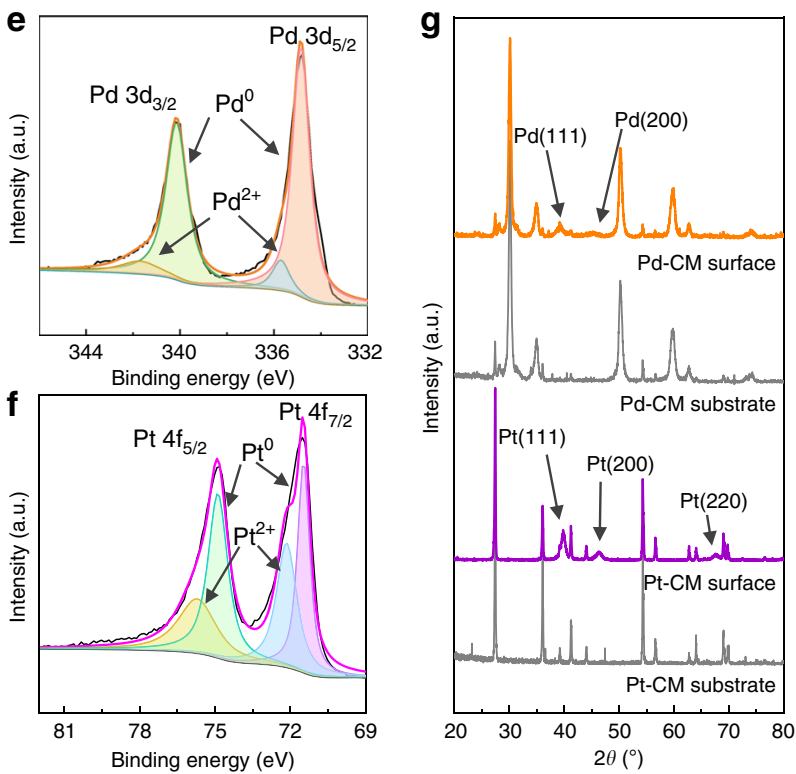

n

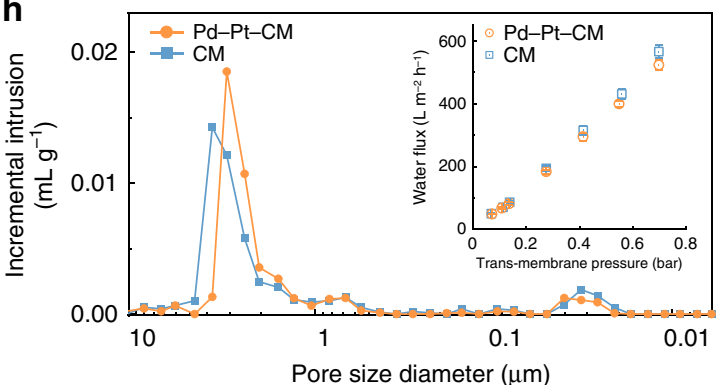

Fig. 1 Fabrication and characterization of the Pd-Pt-CM. a Schematic depicting the fabrication of the Pd-Pt-CM by magnetron sputtering. $\mathbf{b}$, $\mathbf{c}$ SEM crosssection images of the Pd-CM and Pt-CM surfaces, overlapped with EDS mapping of Zr (yellow), O (blue), Ti (green), and Pd (red) or Pt (purple) elements. The insets illustrate the SEM surface images of the respective functionalized membranes overlapped with EDS mapping of Pd (orange) or Pt (purple)

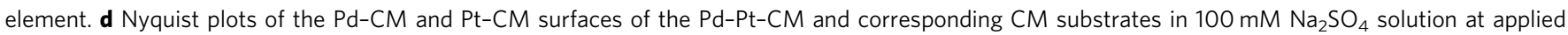
frequencies varied from 106-1 Hz. e, $\mathbf{f}$ XPS spectra of the Pd $3 d$ and Pt $4 f$ on the Pd-Pt-CM, respectively. $\mathbf{g}$ Grazing incidence XRD patterns of the Pd-CM and Pt-CM surfaces of the Pd-Pt-CM with their respective CM substrates. $\mathbf{h}$ Pore size distributions of the Pd-Pt-CM (orange circles) and the pristine CM

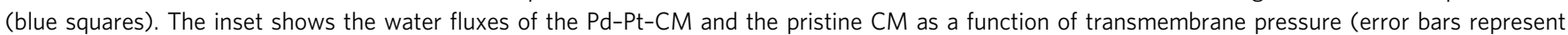
standard deviation from triplicate experiments).

spectroscopy (XPS) and the grazing incidence X-ray diffraction (GIXRD). XPS peaks of Pd $3 d_{3 / 2}$ and Pd $3 d_{5 / 2}$, centered at 340.2 and $335.1 \mathrm{eV}$ (Fig. 1e), suggest that $\mathrm{Pd}^{0}$ is the dominant component with minor $\mathrm{Pd}^{2+}$ coexisting on the $\mathrm{Pd}-\mathrm{CM}$ surface ${ }^{41}$, possibly due to surface oxidation. Similarly, the deconvoluted peaks of Pt $4 f_{5 / 2}$ and Pt $4 f_{7 / 2}$ at binding energies of 74.8 and $71.5 \mathrm{eV}$ (Fig. 1f) indicate the predominance of $\mathrm{Pt}^{0}$ along with partially oxidized $\mathrm{Pt}^{2+}$ on the $\mathrm{Pt}-\mathrm{CM}$ surface $\mathrm{e}^{42}$ (XPS survey spectra is provided in Supplementary Fig. 5). The $\mathrm{Pt}^{2+}$ signal is likely ascribed to the oxidation of $\mathrm{Pt}^{0}$ on the near-surface of the anodic membrane region since XPS can only retrieve information $<10 \mathrm{~nm}$ past the surface of the sample ${ }^{43}$. Notably, the bulk sputtered Pt underneath the anodic membrane surface is mainly composed of $\mathrm{Pt}^{0}$, the more thermodynamically stable Pt species. The XRD analysis reveals that the Pd-CM surface (Fig. 1g, orange) exhibits characteristic diffraction peaks of the (111) and (200) planes of $\mathrm{Pd}^{0}$ (JCPDS No. 46-1043) with a face-centered cubic (fcc) crystal structure at $39.2^{\circ}$ and $45.5^{\circ}$, respectively ${ }^{44}$. The other peaks correspond to rutile (JCPDS No. 73-1232) and zirconium oxide (JCPDS No. 49-1642), indicative of the CM substrate. The presence of crystalline $\mathrm{Pt}$ for the $\mathrm{Pt}-\mathrm{CM}$ surface (Fig. 1g, purple) is corroborated by the diffraction peaks at $39.7^{\circ}$, $46.5^{\circ}$, and $67.7^{\circ}$, consistent with (111), (200), and (220) planes of the fcc $\mathrm{Pt}^{0}$ (JCPDS No. 04-0802) ${ }^{45}$. The mean nanoparticle sizes of
Pd and Pt are calculated as 20.1 and $22.8 \mathrm{~nm}$, respectively, using the Scherrer equation ${ }^{46}$. Notably, the high dispersion of the nano-sized $\mathrm{Pd}$ and Pt is indicated by the broadening of the XRD diffraction peaks ${ }^{47}$, as compared with the intensive peaks of the pristine CM grains (Fig. 1g, gray).

We further analyzed the influence of sputtering on membrane performance. The resembling pore size distributions (Fig. 1h) of the $\mathrm{Pd}-\mathrm{Pt}-\mathrm{CM}$ and the pristine CM suggest a negligible effect of sputtering on membrane structure. The inset in Fig. $1 \mathrm{~h}$ also shows that the $\mathrm{Pd}-\mathrm{Pt}-\mathrm{CM}$ has comparable water flux as the pristine CM, indicating the negligible influence of sputtering on membrane permeability. We also observed reduced surface roughness of both functionalized surfaces of the $\mathrm{Pd}-\mathrm{Pt}-\mathrm{CM}$ comparing with those of the pristine CM (Supplementary Fig. 6), implying that the seeding of $\mathrm{Pd}$ and $\mathrm{Pt}$ nanoparticles smooths the surface morphology. In addition, the $\mathrm{Pd}-\mathrm{Pt}-\mathrm{CM}$ possesses hydrophilic surface properties as the pristine $\mathrm{CM}$, as evidenced by the similar water contact angles of the Pd-Pt-CM $\left(21^{\circ}\right)$ and CM $\left(19^{\circ}\right)$ (Supplementary Fig. 7). The smooth surface and hydrophilic nature of the $\mathrm{Pd}-\mathrm{Pt}-\mathrm{CM}$ suggest a lessened fouling potential by organic molecules ${ }^{35,37}$ and thus more efficient electron transfer during filtration. 
a

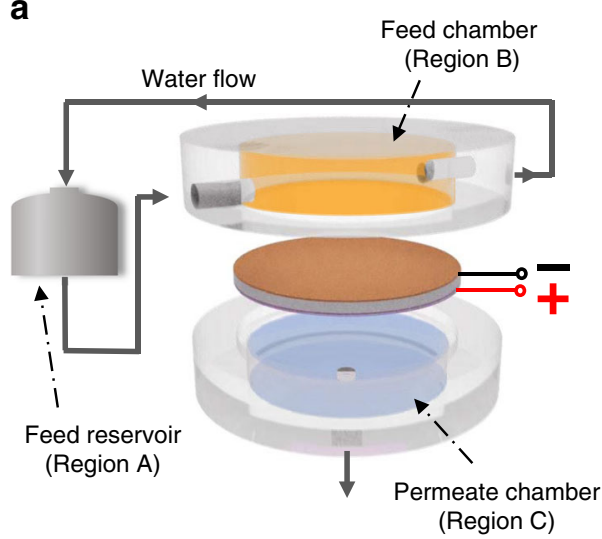

b

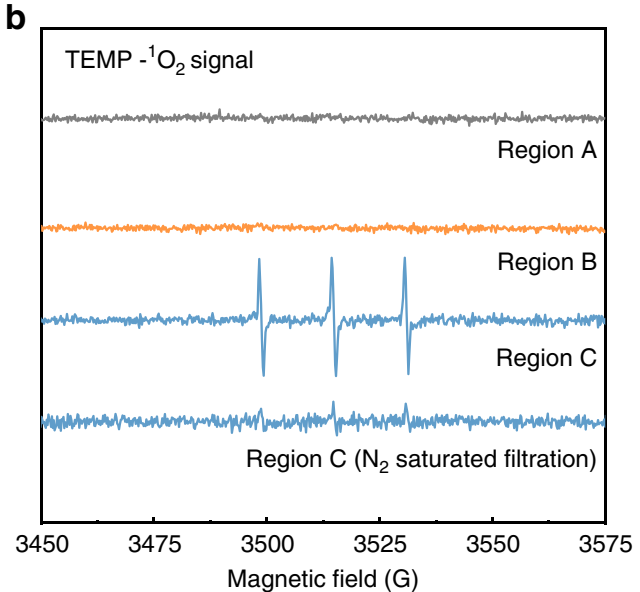

c

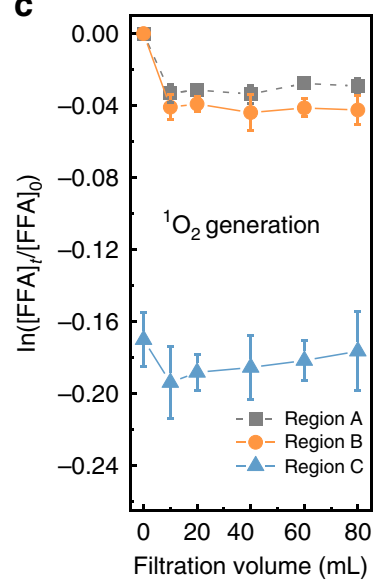

e

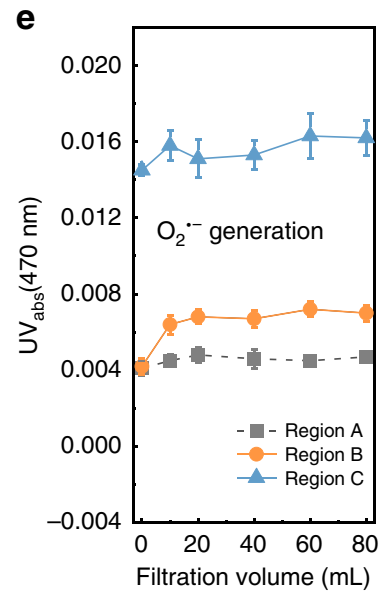

d

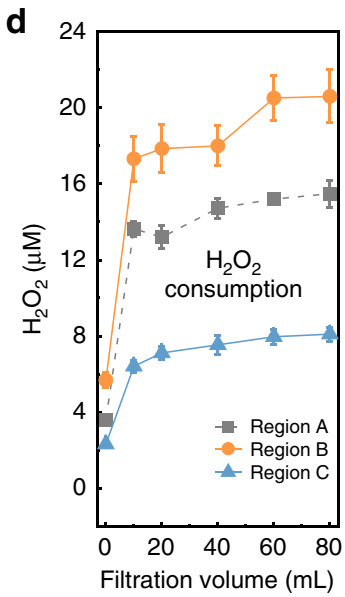

f

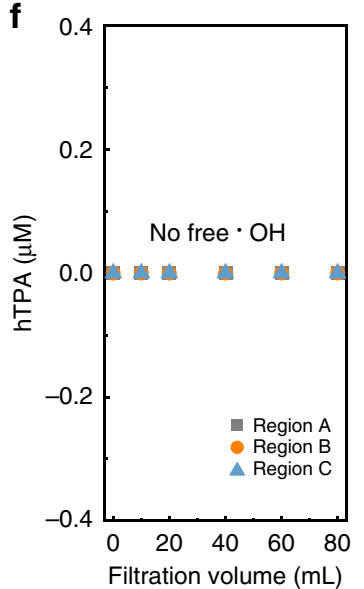

Fig. 2 Spatiotemporal distribution of reactive oxygen species (ROS) generated in the Pd-Pt-CM. a Schematic illustrating the cross-flow filtration system containing a feed reservoir (Region $\mathrm{A}$, gray) and an electrofiltration module with a $12 \mathrm{~mL}$ feed chamber (Region $\mathrm{B}$, orange), a $12 \mathrm{~mL}$ permeate chamber (Region C, blue), and the Pd-Pt-CM. b EPR analysis for ${ }^{1} \mathrm{O}_{2}$ in different regions of the filtration system using 2,2,6,6-tetramethylpiperidine (TEMP, 25 mM) as the trapping agent. EPR measurement of the TEMP-1 $\mathrm{O}_{2}$ adduct in the permeate (Region $\mathrm{C}$ ) of the filtration system using an $\mathrm{N}_{2}$-saturated feed solution is conducted for comparison. ${ }^{1} \mathrm{O}_{2}$ generation indicated by the degradation of furfuryl alcohol (FFA, $50 \mu M$ ). d $\mathrm{H}_{2} \mathrm{O}_{2}$ detection measured by Amplex Red color reaction. e Detection of $\mathrm{O}_{2}{ }^{\bullet-}$ by using 2,3-Bis-(2-methoxy-4-nitro-5-sulfophenyl)-2H-tetrazolium-5-carboxanilide (XTT, $100 \mu M$ ) as the probe. f $\bullet \mathrm{OH}$ measurement by applying terephthalate (TPA, $1 \mathrm{mM}$ ) which reacts with $\bullet \mathrm{OH}$ to form hydroxyterephthalate (hTPA). Error bars represent standard deviations from triplicate experiments.

Spatiotemporal distribution of ${ }^{1} \mathrm{O}_{2}$ and other $\mathrm{ROS}$ in Pd-Pt-CM. Electrocatalytic filtration with the Pd-Pt-CM was conducted in a customized cross-flow filtration device (Supplementary Fig. 8). As shown schematically in Fig. 2a, the $\mathrm{Pd}-\mathrm{Pt}-\mathrm{CM}$ was mounted in-between a feed chamber (Region B, orange) and a permeate chamber (Region C, blue). In our setup, the Pd-CM surface functioning as a cathode faced the feed chamber, while the Pt-CM surface serving as an anode faced the permeate. The feed solution was circulated within the feed reservoir (Region A, gray) at a cross-flow velocity of $0.8 \mathrm{~L} \mathrm{~min}^{-1}$ under an applied pressure of 0.1 bar.

We first detected singlet oxygen $\left({ }^{1} \mathrm{O}_{2}\right)$ generation by the $\mathrm{Pd}-\mathrm{Pt}-\mathrm{CM}$ electrofiltration with only $\mathrm{Na}_{2} \mathrm{SO}_{4}$ electrolyte as the feed solution. Electron paramagnetic resonance (EPR) spectra (Fig. 2b) showed that by applying the trapping agent 2,2,6,6-tetramethylpiperidine (TEMP), the typical triplet signal $(1: 1: 1, \mathrm{a}(\mathrm{N})=16.9 \mathrm{G})$ of 2,2,6,6-tetramethyl-4-piperidinol-N-oxyl (TEMPO) in Region C (blue line) was observed, indicating the presence of ${ }^{1} \mathrm{O}_{2}$ in the permeate ${ }^{8,48}$. Detailed EPR measurement is provided in the Supplementary methods; the EPR spectrum of the blank control solution, i.e., $100 \mathrm{mM} \mathrm{Na}_{2} \mathrm{SO}_{4}$ with $25 \mathrm{mM}$ TEMP, is provided in Supplementary Fig. 9. The lack of TEMPO signals in Regions A and B (Fig. 2b, gray and orange lines) suggests that ${ }^{1} \mathrm{O}_{2}$ was generated from the $\mathrm{Pd}-\mathrm{Pt}-\mathrm{CM}$ inner-pore structure during the electrocatalytic filtration. We observed a minimum applied voltage of $1.6 \mathrm{~V}$ for producing ${ }^{1} \mathrm{O}_{2}$ (EPR spectra in Supplementary Fig. 10). Given that side reactions, i.e., water splitting for hydrogen and oxygen evolutions, are intensified at high voltage and thus reducing the Faradaic efficiency ${ }^{49,50}$, a minimum voltage of $1.6 \mathrm{~V}$ was selected for the subsequent experiments. In addition, ${ }^{1} \mathrm{O}_{2}$ production was confirmed by furfuryl alcohol (FFA) probe $^{51}$, which is highly selective to ${ }^{1} \mathrm{O}_{2}$ with a rate constant of $1.2 \times 10^{8} \mathrm{M}^{-1} \mathrm{~s}^{-1}$. Near $17 \%$ degradation of FFA $(50 \mu \mathrm{M})$ was continuously achieved by the $\mathrm{Pd}-\mathrm{Pt}-\mathrm{CM}$ electrified at $1.6 \mathrm{~V}$ (Fig. 2c, Region $\mathrm{C}$, blue triangles), suggesting a constant production of ${ }^{1} \mathrm{O}_{2}$ within the membrane. The detected products of FFA agree well with the oxidation products of FFA by ${ }^{1} \mathrm{O}_{2}$ oxidation ${ }^{32,52}$ (Supplementary Fig. 11; detailed detection methods provided in the Supplementary methods). In contrast, less than 3\% removal of FFA was observed from the Pd-CM surface (Fig. 2c, Region B, orange circles), likely due to adsorption of FFA on the Pd cathode ${ }^{39}(<1 \%$ FFA removal by conventional non-electrocatalytic Pd-Pt-CM filtration is shown in Supplementary Fig. 12, and $<4.5 \%$ FFA 
removal by $\mathrm{N}_{2}$-saturated $\mathrm{Pd}-\mathrm{Pt}-\mathrm{CM}$ electrofiltration is shown in Supplementary Fig. 13).

Decreasing the oxygen level in the feed solution via nitrogen purging substantially reduced the triplet peak of TEMPO (Fig. 2b), suggesting oxygen to be the precursor for the electro-generated ${ }^{1} \mathrm{O}_{2}$. Other ROS potentially produced in situ via the sequential electro-redox reaction during filtration, including hydrogen peroxide $\left(\mathrm{H}_{2} \mathrm{O}_{2}\right)$, superoxide $\left(\mathrm{O}_{2}{ }^{-}\right)$, and hydroxyl radicals $\left({ }^{\bullet} \mathrm{OH}\right)$, could be involved as critical intermediates for ${ }^{1} \mathrm{O}_{2}$ production $^{32,53}$ (detailed ROS measurement provided in the Supplementary methods). Hydrogen peroxide $\left(\mathrm{H}_{2} \mathrm{O}_{2}\right)$ was generated at the vicinity of the Pd-CM surface (Fig. $2 \mathrm{~d}$ ), which we attribute to the two-electron cathodic reduction of $\mathrm{O}_{2}{ }^{50,54}$. $\mathrm{H}_{2} \mathrm{O}_{2}$ tended to accumulate above the $\mathrm{Pd}-\mathrm{CM}$ surface, as evidenced by the higher $\mathrm{H}_{2} \mathrm{O}_{2}$ concentration in Region B (Fig. 2d, orange circles) than that in Region A (Fig. 2d, gray squares). A near twofold decrease of $\mathrm{H}_{2} \mathrm{O}_{2}$ in the permeate (Fig. 2d, blue triangles) indicates that $\mathrm{H}_{2} \mathrm{O}_{2}$ was further consumed within the $\mathrm{Pd}-\mathrm{Pt}-\mathrm{CM}$ inner-pore structure. In contrast, superoxide $\left(\mathrm{O}_{2}{ }^{\bullet-}\right)$ was more notably produced within the $\mathrm{Pd}-\mathrm{Pt}-\mathrm{CM}$, as evidenced by the higher concentration in the permeate (Fig. 2e, blue triangles) as compared with the other regions (Fig. 2e, orange circles and gray squares). $\mathrm{O}_{2}{ }^{--}$accumulation within the Pd-Pt-CM could be attributed to two pathways: (i) oneelectron reduction of $\mathrm{O}_{2}$ via the $\mathrm{Pd}$ cathode ${ }^{50}$ and (ii) oneelectron oxidation of $\mathrm{H}_{2} \mathrm{O}_{2}$ via the $\mathrm{Pt}$ anode ${ }^{54,55}$. In addition, free hydroxyl radicals $\left({ }^{\bullet} \mathrm{OH}\right)$ were not detected within the system (Fig. 2f); we attribute this observation to the intrinsic nature of $\mathrm{Pt}$ as an "active" anode, which exhibits low production of physisorbed $\mathrm{Pt}\left(\bullet^{\circ} \mathrm{OH}\right)^{56}$.

Efficacy and energy efficiency of electrocatalytic ${ }^{1} \mathrm{O}_{2}$ production. The efficacy of the electrocatalytic Pd-Pt-CM for water decontamination was investigated. Sulfamethoxazole (SMX), an antibiotic molecule, was used as a model organic compound, which can be specifically attacked by ${ }^{1} \mathrm{O}_{2}$ via the electron-rich aniline group $^{57}$ (Fig. 3a). As shown in Fig. 3b, the Pd-Pt-CM (i.e., mode I) exhibited an ultra-efficient SMX removal (82.9\%) during a single-pass electrofiltration (detailed SMX measurement provided in the Supplementary methods). The residence time within the membrane is $\sim 23 \mathrm{~s}$ (Supplementary Eq. 3), which is two orders of magnitude lower than the reaction times in current flow-by EC configurations for water decontamination ${ }^{21,58}$. Notably, the uncompromised membrane permeability (Supplementary Fig. 14) indicates negligible fouling during the electrofiltration, further ensuring durable and unimpeded electron transfer within the membrane (as evidenced by the stable current curve in Supplementary Fig. 15). The electrocatalytic performance and stability of the Pd-Pt-CM were also well retained, as shown in Supplementary Fig. 16.

To validate the role of ${ }^{1} \mathrm{O}_{2}$ and other ROS in the efficient SMX removal during the $\mathrm{Pd}-\mathrm{Pt}-\mathrm{CM}$ electrofiltration (i.e., mode I), we have conducted quenching tests using different ROS scavengers. It is well established that sodium azide $\left(\mathrm{NaN}_{3}\right)$, p-benzoquinone (pBQ), catalase, and terephthalic acid (TPA) are specific scavengers for ${ }^{1} \mathrm{O}_{2}, \mathrm{O}_{2}{ }^{\bullet-}, \mathrm{H}_{2} \mathrm{O}_{2}$, and $\cdot \mathrm{OH}$, respectively $7,59-61$. The efficient quenching using $\mathrm{NaN}_{3}$ confirms the main contribution of ${ }^{1} \mathrm{O}_{2}$ to SMX removal in mode I (Fig. 3c). The oxidation products of SMX were also examined and were found to be consistent with oxidation products of SMX by ${ }^{1} \mathrm{O}_{2}$ oxidation ${ }^{57}$ (Supplementary Fig. 17). Considering that ${ }^{1} \mathrm{O}_{2}$ reacts with $\mathrm{SMX}$ at a minimal molar ratio of $1: 1^{57}$, the minimum ${ }^{1} \mathrm{O}_{2}$ yield by the $\mathrm{Pd}-\mathrm{Pt}-\mathrm{CM}$ can thus be calculated as $6.9 \mathrm{mmol}$ per $\mathrm{m}^{3}$ of permeate, and the ${ }^{1} \mathrm{O}_{2}$ yield rate is calculated as $0.3 \mu \mathrm{M} \mathrm{s}^{-1}$ accordingly
(Supplementary Eqs. 4 and 5). In addition, given the considerably low reactivities of $\mathrm{O}_{2}{ }^{\bullet-}$ and $\mathrm{H}_{2} \mathrm{O}_{2}$ with SMX (Supplementary Fig. 18), the observed quenching by pBQ and catalase suggests that $\mathrm{O}_{2} \cdot-$ and $\mathrm{H}_{2} \mathrm{O}_{2}$ are critical intermediates to ${ }^{1} \mathrm{O}_{2}$ production. The insignificant quenching by TPA indicates that free ${ }^{\bullet} \mathrm{OH}$ plays a negligible role in SMX removal in mode I. In addition, $\mathrm{N}_{2}$-saturated filtration with the $\mathrm{Pd}-\mathrm{Pt}-\mathrm{CM}$ significantly suppressed SMX removal, in agreement with the previous EPR result (Fig. 2b), indicating oxygen to be the source of the in situ generated ${ }^{1} \mathrm{O}_{2}$.

We also investigated the contribution of direct electro-redox reactions on either side of the $\mathrm{Pd}-\mathrm{Pt}-\mathrm{CM}$ toward SMX removal via cyclic voltammetry $(\mathrm{CV})$ measurements. At the cathodic $\mathrm{Pd}-\mathrm{CM}$ surface (Fig. 3d), the distinctive CV peak (blue curve) and enhanced current density in the $\mathrm{O}_{2}$-saturated electrolyte compared with that in the $\mathrm{N}_{2}$-saturated electrolyte (black curve), corroborate the generation of $\mathrm{H}_{2} \mathrm{O}_{2}$ via oxygen reduction at the $\mathrm{Pd}-\mathrm{CM}$ cathode. The addition of SMX to the $\mathrm{Pd}-\mathrm{CM}$ cathode (Fig. 3d, orange curve) caused no obvious difference in $\mathrm{CV}$ curves, indicating inert interaction of SMX in direct electroreduction. Similarly, for the anodic $\mathrm{Pt}-\mathrm{CM}$ surface (Fig. 3e), the indiscernible difference in the CV curves following the addition of SMX suggests an insignificant influence of direct electrooxidation towards SMX removal.

The efficacy of the Janus electrocatalytic Pd-Pt-CM (i.e., mode I) was further compared with those of other EC configurations, i.e., single-sided electrocatalytic flow-through Pd-Pt-CM (mode II and III) and electrocatalytic flow-by modes (mode IV and V) (detailed mode schematics in Supplementary Fig. 19). As we observe in Fig. 3b, mode I exhibited an over the threefold and sevenfold increase of SMX removal rate compared with mode II and mode III, respectively, highlighting the paramount importance of the Janus configuration of the electrocatalytic Pd-Pt-CM in enhancing SMX removal compared to single-sided electrocatalytic membrane configurations. Compared to mode I, mode IV and $\mathrm{V}$ demonstrated notably lower SMX removal rates of $<10 \%$ by the $\mathrm{Pd}-\mathrm{Pt}-\mathrm{CM}$, indicating an order of magnitude lower efficiency of flow-by mode than that of flow-through mode. Without adding electricity, conventional membrane filtration in modes VI and VII showed negligible SMX removal. In addition, following a similar trend as the SMX removal efficiency, mode I showed enhanced current density compared with modes II-V (Supplementary Fig. 15), which corroborates the improved transfer of electrons within the confined Janus $\mathrm{Pd}-\mathrm{Pt}-\mathrm{CM}$ porous structures. Taken together, these results collectively emphasize the key role of the electrocatalytic flow-through configuration using both sides of the $\mathrm{Pd}-\mathrm{Pt}-\mathrm{CM}$ as electrodes (i.e., mode I) for highly efficient ${ }^{1} \mathrm{O}_{2}$ production and enhanced electron transfer in a single-pass filtration.

Electric energy consumption is another important consideration in the application of the electrocatalytic membrane. As observed in Fig. 3b (right axis, orange filled squares), mode I exhibited slightly higher energy consumption (detailed calculations in the Supplementary methods), i.e., $13.3 \mathrm{Wh} \mathrm{m}^{-3}$, than those in modes II-V (orange filled squares) mainly due to the higher current density. However, when taking the removal efficacy into account, the specific energy consumption of mode I (i.e., $6.33 \mathrm{Wh} \mathrm{g}^{-1} \mathrm{SMX}$ ) was significantly lower than those of modes II-V (Fig. 3b right axis, blue filled triangles), indicating an enhanced energy efficiency of the Janus electrocatalytic $\mathrm{Pd}-\mathrm{Pt}-\mathrm{CM}$. We further compared the energy consumption of the $\mathrm{Pd}-\mathrm{Pt}-\mathrm{CM}$ (in mode I) with other reported electrocatalytic membranes for similar use of water decontamination (Supplementary Fig. 20). Remarkably, our Pd-Pt-CM (in mode I) had a substantially lower energy consumption than those reported in other studies. 
a

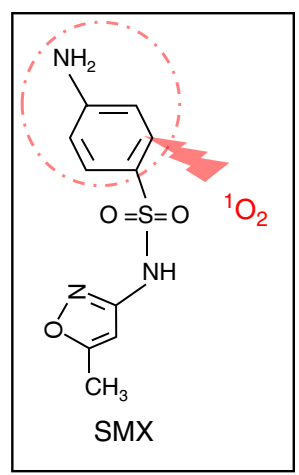

b

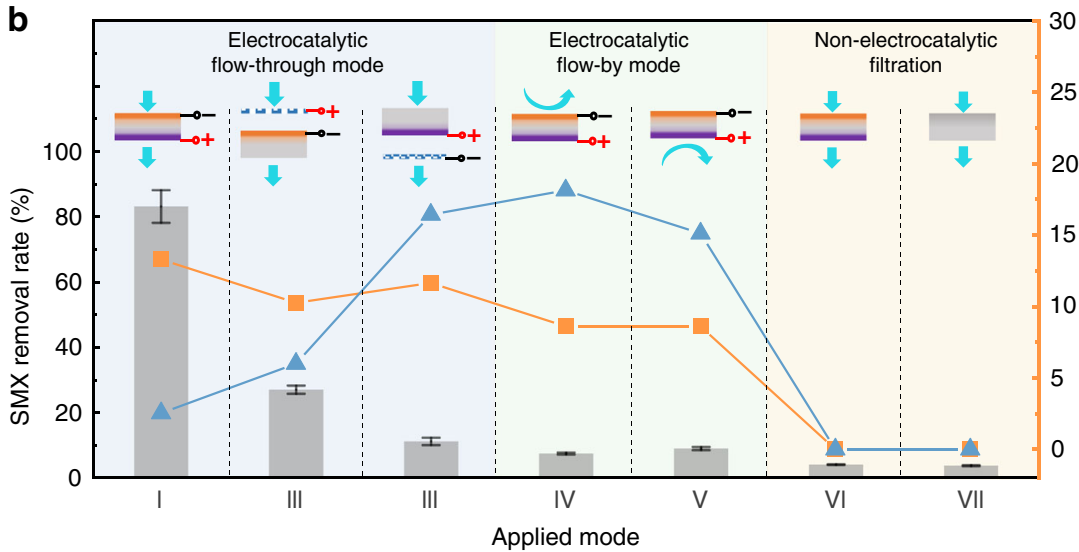

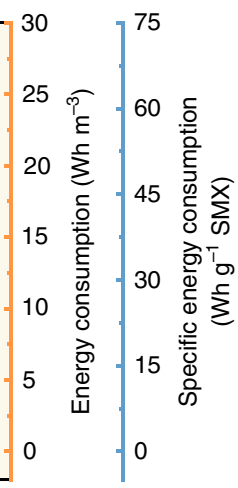
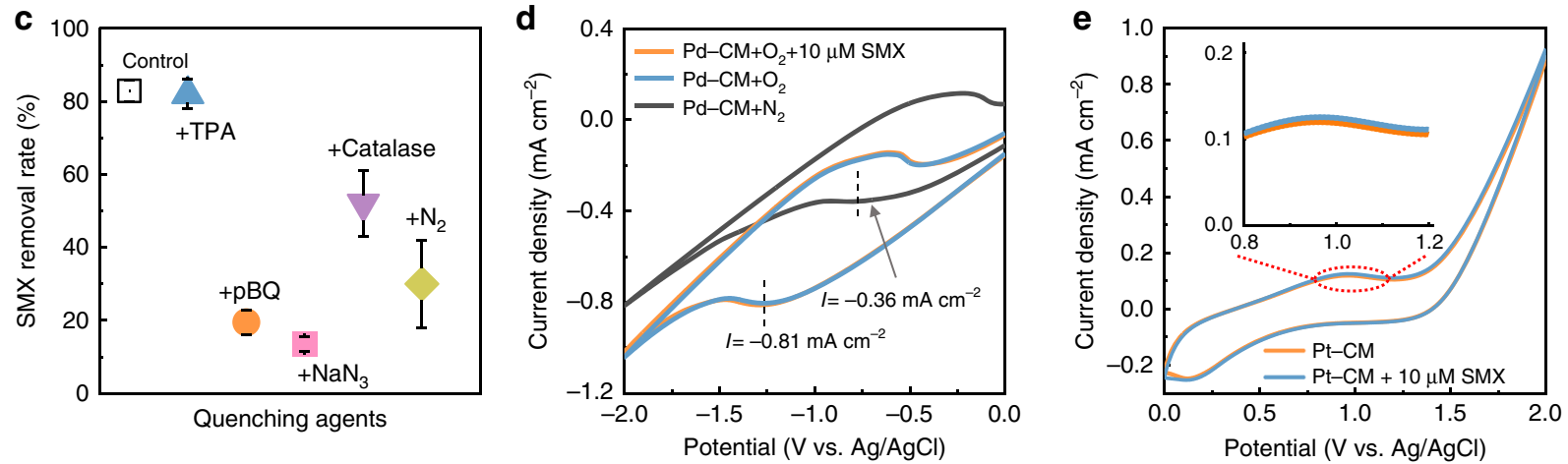

Fig. 3 Effectiveness and energy efficiency of ${ }^{\mathbf{1}} \mathbf{O}_{\mathbf{2}}$ in situ generated by the Pd-Pt-CM. a Schematic illustrating the reaction between ${ }^{1} \mathrm{O}_{2}$ and $\mathrm{SMX}$. $\mathbf{b} \mathrm{SMX}$ removal efficiency and electric energy consumption by $\mathrm{Pd}-\mathrm{Pt}-\mathrm{CM}$ under different electrocatalytic and conventional filtration modes. Modes I-III are for flow-through electrofiltration. For mode, I, the Pd-CM and Pt-CM surfaces of the Pd-Pt-CM serve as cathode and anode, respectively. Modes II and III apply each side of the Pd-Pt-CM as the cathode (mode II) or anode (mode III) and a Ti mesh plate as the counter electrode inserted in the feed chamber (mode II) or permeate chamber (mode III). Modes IV and V are electrocatalytic flow-by modes using the Pd- and Pt-functionalized surfaces as the cathode and anode, respectively. The reaction times of modes IV and $\mathrm{V}$ are the same as the filtration duration in mode I (i.e., 38 min). Mode $\mathrm{VI}$ and $\mathrm{VII}$ are conventional filtration modes using Pd-Pt-CM and CM without applying voltage. For each filtration mode, the feed solution contains $10 \mu \mathrm{M}$ SMX and $100 \mathrm{mM} \mathrm{Na}_{2} \mathrm{SO}_{4}$. Error bars represent the standard deviation from triplicate experiments. In the schematic above each bar, the orange layer and purple layer represent $\mathrm{Pd}-\mathrm{CM}$ and $\mathrm{Pt}-\mathrm{CM}$ surfaces, respectively, and the blue arrows denote the direction of water flow. c ROS quenching by applying 10 mM TPA, $10 \mathrm{mM}$ p-benzoquinone (pBQ), $2 \mathrm{mg} \mathrm{L}^{-1}$ catalase, and $10 \mathrm{mM}$ sodium azide $\left(\mathrm{NaN}_{3}\right)$ as quenchers for $\bullet \mathrm{OH}, \mathrm{O}_{2}{ }^{\bullet-}, \mathrm{H}_{2} \mathrm{O}_{2}$, and ${ }^{1} \mathrm{O}_{2}$, respectively. Measurements were performed in mode I with the respective quenching agent in the feed solution. Error bars represent the standard deviation from triplicate experiments. $\mathbf{d} \mathrm{CV}$ curves of the Pd-CM surface in $100 \mathrm{mM} \mathrm{Na}_{2} \mathrm{SO}_{4}$ electrolyte at a scan rate of $0.1 \mathrm{~V} \mathrm{~s}{ }^{-1}$. e CV curves of the Pt-CM surface in $100 \mathrm{mM} \mathrm{Na}_{2} \mathrm{SO}_{4}$ electrolyte at a scan rate of $0.1 \mathrm{~V} \mathrm{~s}^{-1}$.

\section{Discussion}

Based on our findings discussed above, we propose the following mechanism for the in situ ${ }^{1} \mathrm{O}_{2}$ production (Fig. 4). Due to the lack of TEMP- ${ }^{1} \mathrm{O}_{2}$ EPR fingerprint (Fig. 2b, blue lines) and the inhibited SMX removal (Fig. 3c, yellow diamond) in the absence of $\mathrm{O}_{2}$, we confirm that the presence of the ground state $\mathrm{O}_{2}$ is requisite for producing ${ }^{1} \mathrm{O}_{2}$ by the $\mathrm{Pd}-\mathrm{Pt}-\mathrm{CM}$. Differing from the general route of photosensitization, where sensitizers with the excited-triplet structures directly transfer energy from excitons to the ground state $\mathrm{O}_{2}$ for ${ }^{1} \mathrm{O}_{2}$ generation ${ }^{8,14}$, the electrocatalytic $\mathrm{Pd}-\mathrm{Pt}-\mathrm{CM}$ does not serve as a medium for the direct activation from the inert $\mathrm{O}_{2}$ to ${ }^{1} \mathrm{O}_{2}$. Alternatively, the $\mathrm{Pd}-\mathrm{Pt}-\mathrm{CM}$ allows indirect routes for ${ }^{1} \mathrm{O}_{2}$ synthesis with the ROS $\mathrm{H}_{2} \mathrm{O}_{2}$ and $\mathrm{O}_{2}{ }^{--}$as critical intermediates, as confirmed by the inhibited SMX removal by quenching these ROS (Fig. 3c, orange circle, and purple triangle).

Figure $4 \mathrm{a}-\mathrm{d}$ depict three functional regions in the porous $\mathrm{Pd}-\mathrm{Pt}-\mathrm{CM}$ undergoing a flow-through electrofiltration process (Fig. 4a) and the corresponding spatiotemporal distribution of ROS (Fig. $4 b-d$ ). $\mathrm{H}_{2} \mathrm{O}_{2}$ is first generated by an oxygen reduction reaction (ORR) in the cathodic $\mathrm{Pd}-\mathrm{CM}$ region (Fig. 4b), followed by $\mathrm{O}_{2}{ }^{-}-$accumulation chiefly by the subsequent oxidation of

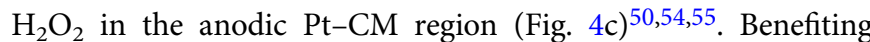
from the continuous production of $\mathrm{H}_{2} \mathrm{O}_{2}$ and $\mathrm{O}_{2}{ }^{--}$, the $\mathrm{Pd}-\mathrm{Pt}-\mathrm{CM}$ triggers two possible pathways for ${ }^{1} \mathrm{O}_{2}$ formation: (i) the Haber-Weiss reaction between $\mathrm{O}_{2}{ }^{-}-/ \mathrm{HO}_{2}{ }^{\bullet}$ and $\mathrm{H}_{2} \mathrm{O}_{2}$ (Fig. 4e, route (1) and (ii) the recombination of $\mathrm{O}_{2}{ }^{\bullet}-/ \mathrm{HO}_{2}{ }^{\bullet}$ (Fig. 4e, route (2) $)^{32,53,62}$. EPR tests further confirm the vital role of $\mathrm{O}_{2}{ }^{--}$and $\mathrm{H}_{2} \mathrm{O}_{2}$ in ${ }^{1} \mathrm{O}_{2}$ formation (Supplementary Figs. 21 and 22). Although an ${ }^{\circ} \mathrm{OH}$ radical-mediated route can also be feasible for ${ }^{1} \mathrm{O}_{2}$ formation ${ }^{32,53}$ (Fig. 4e, route (3), dash line), this pathway is negligible due to the inhibition of the Pt anode for free ${ }^{\bullet} \mathrm{OH}$ generation, as $\mathrm{Pt}$ with its low oxygen evolution overpotential readily transforms the generated physisorbed $\mathrm{Pt}\left(\bullet^{\circ} \mathrm{OH}\right)$ into $\mathrm{PtO}$ superoxide $^{56}$. This is evidenced by the absence of detected $\bullet \mathrm{OH}$ signal during electrofiltration (Fig. 2f) and the marginal inhibition of TPA ( $\bullet^{\circ} \mathrm{OH}$ scavenger) for SMX removal (Fig. 3c, blue triangle).

The formation of $\mathrm{O}_{2}{ }^{--}$intermediates by the $\mathrm{H}_{2} \mathrm{O}_{2}$ oxidation at the anodic $\mathrm{Pt}-\mathrm{CM}$ region, as compared with that by the ORR pathway at the cathodic $\mathrm{Pd}-\mathrm{CM}$ region, is critical for ${ }^{1} \mathrm{O}_{2}$ synthesis in the $\mathrm{Pd}-\mathrm{Pt}-\mathrm{CM}$ (Fig. 4e, thick lines). As the $\mathrm{Pd}$ cathode favors the formation of $\mathrm{H}_{2} \mathrm{O}_{2}$ and $\mathrm{H}_{2} \mathrm{O}$ via a serial twoplus-two-electron transfer in ORR, its generation of $\mathrm{O}_{2}{ }^{-}-$intermediates from the one-electron transfer is minor ${ }^{63,64}$. This 

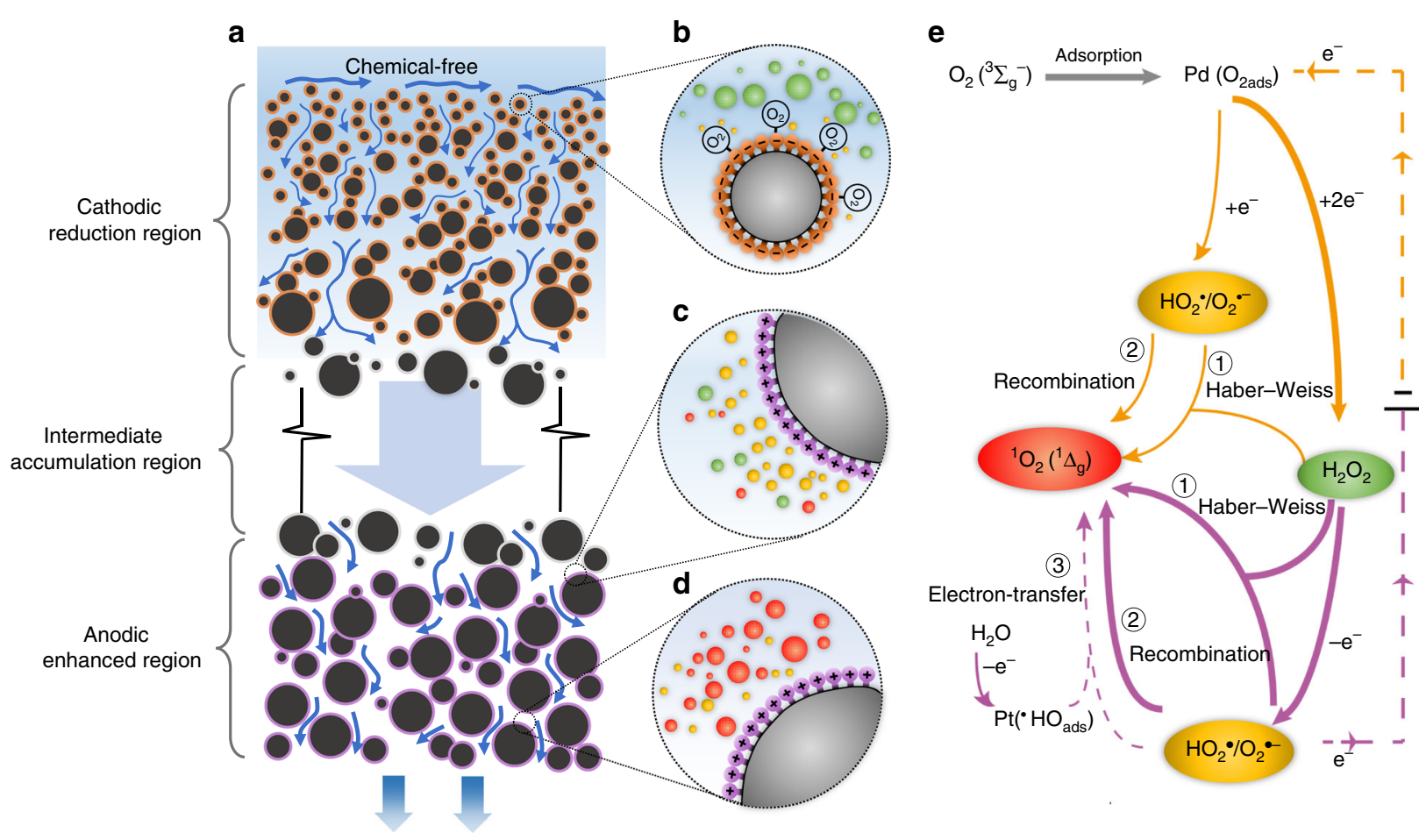

Singlet oxygen production
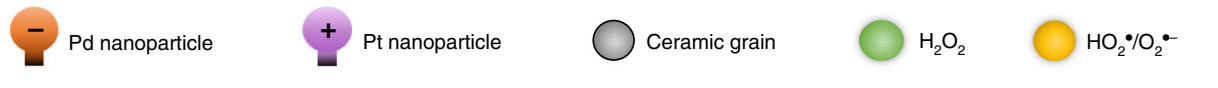

Fig. 4 Proposed mechanism for ${ }^{\mathbf{1}} \mathbf{O}_{\mathbf{2}}$ production by the electrocatalytic Pd-Pt-CM filtration. a Schematic describing the various regions in the Pd-Pt-CM. b Schematic of the cathodic Pd-functionalized (black and orange core-shell balls) membrane region, where $\mathrm{H}_{2} \mathrm{O}_{2}$ (green balls) and $\mathrm{O}_{2}{ }^{\bullet-}$ (yellow balls) are generated via oxygen reduction in close vicinity to the Pd-functionalized pores. c Anodic Pt-functionalized (black and purple core-shell balls) membrane region, where $\mathrm{H}_{2} \mathrm{O}_{2}$ consumption, $\mathrm{O}_{2}{ }^{\bullet-}$ accumulation, and ${ }^{1} \mathrm{O}_{2}$ (red balls) generation occur concurrently. d A zoom-in close-to-bottom Pt-functionalized channel, where ${ }^{1} \mathrm{O}_{2}$ is released throughout the permeate flow. e Proposed reaction pathway of singlet oxygen production. The orange and purple arrows represent the reactions occurring in the cathodic reduction region and anodic enhanced region, respectively. Dashed lines linked to the electric power supply denote the electron transfer.

proposed analysis is also verified by tuning the electrofiltration modes. By shifting from the use of only cathodic Pd-CM (Fig. 3b, mode II) to the use of sequential cathodic Pd-CM and anodic Pt-CM (Fig. 3b, mode I), a significant increase in the removal rate from 27.0 to $82.9 \%$ was observed, corroborating the key role of the anodic Pt-CM in contributing for $\mathrm{O}_{2}{ }^{-}$formation. Additionally, switching the electro-redox sequence, i.e., applying $\mathrm{Pd}-\mathrm{CM}$ as anode facing the feed solution and $\mathrm{Pt}-\mathrm{CM}$ as cathode facing the permeate, fails to produce ${ }^{1} \mathrm{O}_{2}$ (Supplementary Figure 23). These results collectively validate that the electro-redox sequence, which induces sequential generation of $\mathrm{H}_{2} \mathrm{O}_{2}$ and $\mathrm{O}_{2}{ }^{--}$, is critical for the ${ }^{1} \mathrm{O}_{2}$ formation in the $\mathrm{Pd}-\mathrm{Pt}-\mathrm{CM}$.

The distinct material structure of the Pd-Pt-CM, endowed by the confocal magnetron sputtering technique, offers additional mechanistic insights into the favorable ${ }^{1} \mathrm{O}_{2}$ synthesis. One important structural feature achieved by the sputtering is the high dispersion of Pd and Pt nanoparticles (Fig. 1g), which prevents the formation of large agglomerates on the CM substrate ${ }^{65}$. This feature is also evidenced by the negligible changes in permeability and pore size distribution of the $\mathrm{Pd}-\mathrm{Pt}-\mathrm{CM}$ compared to the pristine CM (Fig. 1h). The high dispersion of Pd nanoparticles renders the favorable electrocatalytic formation of $\mathrm{H}_{2} \mathrm{O}_{2}$ over $\mathrm{H}_{2} \mathrm{O}$ in the ORR pathway, which is critical for inducing the subsequent ROS chain reactions (Fig. 4e, thick lines). Given the latter $\mathrm{H}_{2} \mathrm{O}$ product in ORR is formed by a desorption-readsorption of the $\mathrm{H}_{2} \mathrm{O}_{2}$ intermediate on a proximate Pd reactive site ${ }^{64,66}$, the increased interparticle distances of Pd nanoparticles imparted by sputtering prevent $\mathrm{H}_{2} \mathrm{O}_{2}$ from subsequent reduction by adjacent Pd agglomerates. Another important structural feature achieved by the Pd and Pt sputtering is the large sputtered depth in the near-surface regions of both sides of the $\mathrm{Pd}-\mathrm{Pt}-\mathrm{CM}$ (i.e., 60 and $90 \mu \mathrm{m}$ for $\mathrm{Pd}-\mathrm{CM}$ and $\mathrm{Pt}-\mathrm{CM}$ regions from Fig. 1a, c). These sputtered depths are over an order of magnitude greater than the inner-porous reactive lengths of reported electrocatalytic membranes ${ }^{67,68}$. Taken together, the high dispersion of the electro-catalysts, as well as the elongated reactive regions, guarantee maximal exposure of the reactive sites in the Pd-Pt-CM. Furthermore, with the presence of the (100) facet of the Pt nanoparticles, the Pt anodic membrane region inherently favors the spin state of ${ }^{1} \mathrm{O}_{2}$, thus likely facilitating ${ }^{1} \mathrm{O}_{2}$ formation by promoting electron transfer between ${ }^{1} \mathrm{O}_{2}$ precursors adsorbed on the Pt nanoparticles ${ }^{61,69,70}$ (for specific reaction steps see Supplementary Table 1).

Enhanced mass transfer induced by the flow-through electrofiltration is another important feature to promote in situ ${ }^{1} \mathrm{O}_{2}$ formation. The forced convection, together with the confinement of the solution within the membrane inner-pores, synergistically enhances the transfer of electrons and reactants at the membranesolution interface ${ }^{33,71}$. This synergy also facilitates the intimate contact of reactants to maximally exploit their redox capacity for ${ }^{1} \mathrm{O}_{2}$ synthesis ${ }^{72}$. In addition, we carried out an SMX removal test in a batch mode without the forced filtration using the same electrocatalytic Pd-Pt-CM configuration as mode I. As shown in Supplementary Fig. 24, an over tenfold decrease of SMX removal efficiency $(7.4 \%)$ and current density $\left(0.006 \mathrm{~mA} \mathrm{~cm}^{-2}\right)$ compared with those of mode I was observed, thus corroborating the 
enhanced mass and charge transfer by convection within the confined porous membrane regions.

In summary, we have developed a Janus electrocatalytic membrane, which leverages sequential reduction-oxidation reactions in distinct membrane regions for ultra-efficient ${ }^{1} \mathrm{O}_{2}$ synthesis via a flow-through electrofiltration. This automated, sustainable and scalable approach of highly efficient ${ }^{1} \mathrm{O}_{2}$ production and utilization has promising potential in diverse applications, including targeted water purification and in situ sensing in environmental remediation, green organic synthesis, and biomedical engineering. Moreover, we envision that the proposed Janus electrocatalytic membrane geometry, which is radically different from the general assembly of incorporating half-cell reaction with a membrane substrate, will pave the way for future smarter design strategies for high-performance and multifunctional electrocatalytic membranes.

\section{Methods \\ Fabrication of Pd-Pt-CM. The Janus membrane (Pd-Pt-CM) was prepared via confocal magnetron co-sputtering (AJA International ATC 2200). Pd and Pt nanoparticles were sputtered on the feed- and permeate-side surfaces of a ceramic membrane $(\mathrm{CM})$ substrate from respective targets with purity $\geq 99.95 \%$. The sputtering targets were aligned in tetrahedral configuration with an angle and distance to the $\mathrm{CM}$ substrate set as $30^{\circ}$ and $18 \mathrm{~cm}$, respectively. A base pressure was retained at below $10^{-7} \mathrm{~Pa}$ prior to sputtering. Ultrapure argon gas was then employed for providing a working pressure of $0.3 \mathrm{~Pa}$ to eliminate possible con- tamination in the sputtering chamber. Subsequently, we placed the CM substrate on a silicon holder with its feed-side surface facing to the Pd target, followed by initiating Pd sputtering at a power of $30 \mathrm{~W}$ with a deposition rate of $2.1 \mathrm{~nm} \mathrm{~min}^{-1}$. The sputtering of $\mathrm{Pt}$ on the permeate-side surface of $\mathrm{CM}$ was then conducted at identical power with a deposition rate of $2.3 \mathrm{~nm} \mathrm{~min}-1$. Deposition thicknesses for the Pd- and Pt-functionalized surfaces were controlled as $\sim 30 \mathrm{~nm}$ by a quartz thickness gauge meter positioned in the center of the sputtering chamber.}

Characterization of Pd-Pt-CM. SEM (SU8230, Hitachi) coupled with X-ray energy dispersive spectroscopy (EDS, XFlash 5060FQ, Bruker) was employed to investigate the morphology and elemental distribution of the Pd-Pt-CM and the pristine CM substrate. The roughness of the $\mathrm{Pd}-\mathrm{CM}$ surface and $\mathrm{Pt}-\mathrm{CM}$ surface was measured by atomic force microscopy (Dimension Fastscan, Bruker) and a Zygo Nexview 3D optical profiler (AMETEK), respectively. Grazing incidence Xray diffraction (GI-XRD, Smart lab, Rigaku) was applied for evaluating the crystal structures of the $\mathrm{Pd}-\mathrm{Pt}-\mathrm{CM}$ and the $\mathrm{CM}$ substrate. X-ray photoelectron spectroscopy (XPS, VersaProbe II, PHI) was used to characterize the elemental composition of the functionalized membrane surfaces. Membrane pore size distribution was measured by AutoPore V-mercury intrusion porosimetry. The water contact angle was measured by the sessile drop method using a contact angle goniometer (OneAttension, Biolin Scientific).

Electrofiltration procedure. Electrofiltration experiments were conducted using a cross-flow membrane filtration system (Supplementary Fig. 8). The membrane system consists of a $12-\mathrm{mL}$ feed chamber and a $12-\mathrm{mL}$ permeate chamber. $\mathrm{Pd}-\mathrm{Pt}-\mathrm{CM}$ was inserted in-between the feed and permeate chambers; Pd-CM surface faced the feed chamber, while Pt-CM surface faced the permeate chamber. The Pd-CM and Pt-CM surfaces serving as cathode and anode, respectively, were connected to a DC supply (E3617A, HEWLETT PACKARD) via carbon tape. Porous titanium (Ti) mesh plate with an identical surface area as Pd-Pt-CM $\left(17.34 \mathrm{~cm}^{2}\right)$ was placed in each chamber and used as a counter electrode in specific flow-through modes (i.e., mode II and III in Fig. 3b). A constant voltage of $1.6 \mathrm{~V}$ was applied to the Pd-Pt-CM throughout the filtration experiments, and a multimeter (Fluke 87-V, Everett, WA) was used for current measurement.

Experiments were carried out in flow-through and flow-by modes. For each mode, feed solution was circulated between the feed chamber (i.e., Region B in Fig. 2a) and feed reservoir (i.e., Region A in Fig. 2a) at a flow velocity of $0.8 \mathrm{~L} \mathrm{~min}^{-1}$ by a gear pump (Cole-Parmer Instrument Company, Vernon Hills, IL, USA). In flow-through mode, the feed solution flowed through the membrane at a constant transmembrane pressure of $0.1 \mathrm{bar}$, while in the flow-by mode, the feed solution flowed tangent to the membrane surface.

Electrochemical measurements. Electrochemical performance of the Pd-Pt-CM was analyzed by an electrochemical workstation (CHI 660E, CH Instruments) using a typical three-electrode configuration electrochemical cell. We applied one membrane surface as the working electrode, a platinum wire as the counter electrode, and an $\mathrm{Ag} / \mathrm{AgCl}$ electrode as the reference electrode, in $100 \mathrm{mM} \mathrm{Na} \mathrm{SO}_{4}$ solution. EIS for each membrane surface was conducted by applying frequencies varied from $10^{6}$ to $1 \mathrm{~Hz}$. CV curves of each membrane surface were collected at a scan rate of $0.1 \mathrm{~V} \mathrm{~s}^{-1}$ in either $\mathrm{O}_{2}$-saturated or $\mathrm{N}_{2}$-saturated $\mathrm{Na}_{2} \mathrm{SO}_{4}$ solution $(100 \mathrm{mM})$. Pure nitrogen or oxygen gas was used to purge the electrolyte for $1 \mathrm{~h}$ prior to the tests.

\section{Data availability}

The data that support the findings of this study are available from the corresponding authors upon reasonable request.

Received: 7 June 2020; Accepted: 28 October 2020;

Published online: 04 December 2020

\section{References}

1. Kautsky, H. Quenching of luminescence by oxygen. Trans. Faraday Soc. 35, 216-219 (1939)

2. Lion, Y., Delmelle, M. \& Van De Vorst, A. New method of detecting singlet oxygen production. Nature 263, 442-443 (1976).

3. Zepp, R. G., Wolfe, N. L., Baughman, G. L. \& Hollis, R. C. Singlet oxygen in natural waters. Nature 267, 421-423 (1977).

4. Cleveland, J. L. \& Kastan, M. B. A radical approach to treatment. Nature 407, 309-311 (2000).

5. Theopold, U. A bad boy comes good. Nature 461, 486-487 (2009).

6. Kalay, E., Kılıç, H., Catir, M., Cakici, M. \& Kazaz, C. Generation of singlet oxygen (1O2) from hydrogen peroxide decomposition by in situ generated hypervalent iodoarene reagents. Pure Appl. Chem. 86, 945-952 (2014).

7. Di Mascio, P. et al. Singlet molecular oxygen reactions with nucleic acids, lipids, and proteins. Chem. Rev. 119, 2043-2086 (2019).

8. Rengifo-Herrera, J. A. et al. Abatement of organics and Escherichia coli by N, $\mathrm{S}$ co-doped $\mathrm{TiO} 2$ under $\mathrm{UV}$ and visible light. Implications of the formation of singlet oxygen (1O2) under visible light. Appl. Catal. B Environ. 88, 398-406 (2009).

9. Duarte, V. et al. Oxaluric acid as the major product of singlet oxygenmediated oxidation of 8-oxo-7,8-dihydroguanine in DNA. J. Am. Chem. Soc. 122, 12622-12628 (2000)

10. García-Fresnadillo, D. Singlet oxygen photosensitizing materials for point-ofuse water disinfection with solar reactors. ChemPhotoChem 2, 512-534 (2018).

11. Wang, D. et al. Self-assembled single-atom nanozyme for enhanced photodynamic therapy treatment of tumor. Nat. Commun. 11, 1-13 (2020).

12. Ghogare, A. A. \& Greer, A. Using singlet oxygen to synthesize natural products and drugs. Chem. Rev. 116, 9994-10034 (2016).

13. Adarsh, N., Avirah, R. R. \& Ramaiah, D. Tuning photosensitized singlet oxygen generation efficiency of novel Aza-BODIPY dyes. Org. Lett. 12, 5720-5723 (2010).

14. Shi, L., Hernandez, B. \& Selke, M. Singlet oxygen generation from watersoluble quantum dot-organic dye nanocomposites. J. Am. Chem. Soc. 128, 6278-6279 (2006).

15. Al-Nu'airat, J. et al. Reaction of phenol with singlet oxygen. Phys. Chem. Chem. Phys. 21, 171-183 (2018).

16. Klebanoff, S. J. Myeloperoxidase: friend and foe. J. Leukoc. Biol. 77, 598-625 (2005).

17. Kanofsky, J. \& Axelrod, B. Singlet oxygen production by soybean lipoxygenase isozymes. J. Biol. Chem. 261, 1099-1104 (1986).

18. Pierlot, C., Aubry, J.-M., Briviba, K., Sies, H. \& Mascio, P. D. Naphthalene endoperoxides as generators of singlet oxygen in biological media. In Methods in Enzymology (eds Packer, L. \& Sies, H.) Vol. 319. (Academic Press, 2000).

19. Nazmutdinov, R. R., Santos, E. \& Schmickler, W. Spin effects in oxygen electrocatalysis: a discussion. Electrochem. Commun. 33, 14-17 (2013).

20. Tian, S. et al. Cyanide oxidation by singlet oxygen generated via reaction between $\mathrm{H} 2 \mathrm{O} 2$ from cathodic reduction and $\mathrm{OCl}(-)$ from anodic oxidation. $J$. Colloid Interface Sci. 482, 205-211 (2016).

21. Liu, Z. et al. Electrochemical activation of peroxymonosulfate with ACF cathode: kinetics, influencing factors, mechanism, and application potential. Water Res. 159, 111-121 (2019).

22. Li, J., Ai, Z. \& Zhang, L. Design of a neutral electro-Fenton system with $\mathrm{Fe} @ \mathrm{Fe} 2 \mathrm{O} 3 / \mathrm{ACF}$ composite cathode for wastewater treatment. J. Hazard. Mater. 164, 18-25 (2009).

23. Nazari, R. et al. Immobilized palladium-catalyzed electro-Fenton's degradation of chlorobenzene in groundwater. Chemosphere 216, 556-563 (2019).

24. Fu, W. C., Wang, X. Y., Zheng, J. J., Liu, M. X. \& Wang, Z. W. Antifouling performance and mechanisms in an electrochemical ceramic membrane reactor for wastewater treatment. J. Membr. Sci. 570, 355-361 (2019).

25. Mayeda, E. A. \& Bard, A. J. Production of singlet oxygen in electrogenerated radical ion electron transfer reactions. J. Am. Chem. Soc. 95, 6223-6226 (1973). 
26. You, Y. Chemical tools for the generation and detection of singlet oxygen. Org. Biomol. Chem. 16, 4044-4060 (2018).

27. Moreira, F. C., Boaventura, R. A. R., Brillas, E. \& Vilar, V. J. P. Electrochemical advanced oxidation processes: a review on their application to synthetic and real wastewaters. Appl. Catal. B Environ. 202, 217-261 (2017).

28. Gao, F. \& Nebel, C. E. Electrically conductive diamond membrane for electrochemical separation processes. ACS Appl. Mater. Interfaces 8, 18640-18646 (2016).

29. Liu, Z. M. et al. Aqueous tetracycline degradation by coal-based carbon electrocatalytic filtration membrane: effect of nano antimony-doped tin dioxide coating. Chem. Eng. J. 314, 59-68 (2017).

30. Sun, M. \& Li, J. Graphene oxide membranes: functional structures, preparation and environmental applications. Nano Today 20, 121-137 (2018).

31. Liu, L., Lee, W., Huang, Z., Scholz, R. \& Gösele, U. Fabrication and characterization of a flow-through nanoporous gold nanowire/AAO composite membrane. Nanotechnology 19, 335604 (2008).

32. Yang, Z., Qian, J., Yu, A. \& Pan, B. Singlet oxygen mediated iron-based Fenton-like catalysis under nanoconfinement. Proc. Natl Acad. Sci. USA 116, 6659-6664 (2019)

33. Ji, Q. et al. Microfluidic flow through polyaniline supported by lamellarstructured graphene for mass-transfer-enhanced electrocatalytic reduction of hexavalent chromium. Environ. Sci. Technol. 49, 13534-13541 (2015).

34. Gayen, P. et al. Electrocatalytic reduction of nitrate using magnéli phase $\mathrm{TiO} 2$ reactive electrochemical membranes doped with Pd-based catalysts. Environ. Sci. Technol. 52, 9370-9379 (2018).

35. Lu, D., Zhang, T., Gutierrez, L., Ma, J. \& Croué, J.-P. Influence of surface properties of filtration-layer metal oxide on ceramic membrane fouling during ultrafiltration of oil/water emulsion. Environ. Sci. Technol. 50, 4668-4674 (2016).

36. Zhao, Y. et al. Interaction analysis between gravity-driven ceramic membrane and smaller organic matter: implications for retention and fouling mechanism in ultralow pressure-driven filtration system. Environ. Sci. Technol. 52, 13718-13727 (2018)

37. Zhao, Y. et al. Synergistic oxidation-filtration process analysis of catalytic $\mathrm{CuFe2O}$-tailored ceramic membrane filtration via peroxymonosulfate activation for humic acid treatment. Water Res. 171, 115387 (2020).

38. Ren, X. et al. Current progress of Pt and Pt-based electrocatalysts used for fuel cells. Sustain. Energy Fuels 4, 15-30 (2020).

39. Xie, W. et al. Electrocatalytic activity of Pd-loaded $\mathrm{Ti} / \mathrm{TiO} 2$ nanotubes cathode for TCE reduction in groundwater. Water Res. 47, 3573-3582 (2013).

40. Mei, B.-A., Munteshari, O., Lau, J., Dunn, B. \& Pilon, L. Physical interpretations of Nyquist plots for EDLC electrodes and devices. J. Phys. Chem. C 122, 194-206 (2018).

41. Niu, S. et al. Nanoscale Pd supported on 3D porous carbon for enhanced selective oxidation of benzyl alcohol. RSC Adv. 7, 25885-25890 (2017).

42. Vovk, E. I., Kalinkin, A. V., Smirnov, M. Y., Klembovskii, I. O. \& Bukhtiyarov, V. I. XPS study of stability and reactivity of oxidized Pt nanoparticles supported on TiO2. J. Phys. Chem. C 121, 17297-17304 (2017).

43. Gilbert, J. B., Rubner, M. F. \& Cohen, R. E. Depth-profiling X-ray photoelectron spectroscopy (XPS) analysis of interlayer diffusion in polyelectrolyte multilayers. Proc. Natl Acad. Sci. USA 110, 6651-6656 (2013).

44. Patil, P. T., Dimitrov, A., Radnik, J. \& Kemnitz, E. Sol-gel synthesis of metal fluoride supported Pd catalysts for Suzuki coupling. J. Mater. Chem. A 18, $1632-1635$ (2008).

45. Xu, G.-R., Hui, J.-J., Huang, T., Chen, Y. \& Lee, J.-M. Platinum nanocuboids supported on reduced graphene oxide as efficient electrocatalyst for the hydrogen evolution reaction. J. Power Sources 285, 393-399 (2015).

46. Scherrer, P. Estimation of the size and internal structure of colloidal particles by means of röntgen. Nachr. Ges. Wiss. Göttingen 2, 96-100 (1918).

47. Venezia, A. et al. Catalytic CO oxidation over pumice supported Pd-Ag catalysts. Appl. Catal. A 211, 167-174 (2001).

48. Yang, Y., Banerjee, G., Brudvig, G. W., Kim, J. H. \& Pignatello, J. J. Oxidation of organic compounds in water by unactivated peroxymonosulfate. Environ. Sci. Technol. 52, 5911-5919 (2018)

49. Feng, Y., Yang, L., Liu, J. \& Logan, B. E. Electrochemical technologies for wastewater treatment and resource reclamation. Environ. Sci. 2, 800-831 (2016).

50. Zhou, W., Meng, X., Gao J. \& Alshawabkeh, A. N. Hydrogen peroxide generation from $\mathrm{O} 2$ electroreduction for environmental remediation: a stateof-the-art review. Chemosphere 225, 588-607 (2019).

51. Appiani, E., Ossola, R., Latch, D. E., Erickson, P. R. \& McNeill, K. Aqueous singlet oxygen reaction kinetics of furfuryl alcohol: effect of temperature, $\mathrm{pH}$, and salt content. Environ. Sci. 19, 507-516 (2017).

52. Braun, A. M. et al. $(2+4)$-Cycloaddition with singlet oxygen. 17Olnvestigation of the reactivity of furfuryl alcohol endoperoxide. Photochem. Photobiol. 70, 868-874 (1999).

53. Khan, A. U. \& Kasha, M. Singlet molecular oxygen in the Haber-Weiss reaction. Proc. Natl Acad. Sci. USA 91, 12365-12367 (1994).
54. Coria, G., Sirés, I., Brillas, E. \& Nava, J. L. Influence of the anode material on the degradation of naproxen by Fenton-based electrochemical processes. Chem. Eng. J. 304, 817-825 (2016).

55. Ridruejo, C. et al. Electrochemical oxidation of anesthetic tetracaine in aqueous medium. Influence of the anode and matrix composition. Chem. Eng. J. 326, 811-819 (2017).

56. Panizza, M. \& Cerisola, G. Direct and mediated anodic oxidation of organic pollutants. Chem. Rev. 109, 6541-6569 (2009).

57. Zhou, Y. et al. Activation of peroxymonosulfate by phenols: Important role of quinone intermediates and involvement of singlet oxygen. Water Res. 125, 209-218 (2017).

58. Huang, Y. W., Zhou, T., Wu, X. H. \& Mao, J. Efficient sonoelectrochemical decomposition of sulfamethoxazole adopting common Pt/graphite electrodes: The mechanism and favorable pathways. Ultrason. Sonochem. 38, 735-743 (2017).

59. Gligorovski, S., Strekowski, R., Barbati, S. \& Vione, D. Environmental implications of hydroxyl radicals $\left(\left(^{*}\right) \mathrm{OH}\right)$. Chem. Rev. 115, 13051-13092 (2015).

60. Hayyan, M., Hashim, M. A. \& AlNashef, I. M. Superoxide ion: generation and chemical implications. Chem. Rev. 116, 3029-3085 (2016).

61. Long, R. et al. Surface facet of palladium nanocrystals: a key parameter to the activation of molecular oxygen for organic catalysis and cancer treatment. J. Am. Chem. Soc. 135, 3200-3207 (2013).

62. Koppenol, W. Reactions involving singlet oxygen and the superoxide anion. Nature 262, 420-421 (1976).

63. Shao, M. Palladium-based electrocatalysts for hydrogen oxidation and oxygen reduction reactions. J. Power Sources 196, 2433-2444 (2011).

64. Mittermeier, T., Weiß, A., Gasteiger, H. A. \& Hasché, F. Monometallic palladium for oxygen reduction in pem fuel cells: particle-size effect, reaction mechanism, and voltage cycling stability. J. Electrochem. Soc. 164, F1081-F1089 (2017).

65. Fabbri, E. et al. The effect of platinum nanoparticle distribution on oxygen electroreduction activity and selectivity. ChemCatChem 6, 1410-1418 (2014).

66. Fortunato, G. V. et al. Impact of palladium loading and interparticle distance on the selectivity for the oxygen reduction reaction toward hydrogen peroxide. J. Phys. Chem. C 122, 15878-15885 (2018).

67. Wang, X. et al. In situ electrochemical generation of reactive chlorine species for efficient ultrafiltration membrane self-cleaning. Environ. Sci. Technol. 54, 6997-7007 (2020).

68. $\mathrm{Li}, \mathrm{X}$. et al. Using $\mathrm{TiO} 2$ mesoflower interlayer in tubular porous titanium membranes for enhanced electrocatalytic filtration. Electrochim. Acta $\mathbf{2 1 8}$ 318-324 (2016).

69. Vankayala, R., Sagadevan, A., Vijayaraghavan, P., Kuo, C. L. \& Hwang, K. C. Metal nanoparticles sensitize the formation of singlet oxygen. Angew. Chem. Int. Ed. 50, 10640-10644 (2011).

70. Chen, Y.-Z. et al. Singlet oxygen-engaged selective photo-oxidation over Pt nanocrystals/porphyrinic MOF: the roles of photothermal effect and Pt electronic state. J. Am. Chem. Soc. 139, 2035-2044 (2017).

71. Gao, G., Zhang, Q., Hao, Z. \& Vecitis, C. D. Carbon nanotube membrane stack for flow-through sequential regenerative electro-fenton. Environ. Sci. Technol. 49, 2375-2383 (2015).

72. Kjeang, E., Michel, R., Harrington, D. A., Djilali, N. \& Sinton, D. A microfluidic fuel cell with flow-through porous electrodes. J. Am. Chem. Soc. 130, 4000-4006 (2008).

\section{Acknowledgements}

The authors acknowledge the use of facilities supported by the Yale Institute for Nanoscience and Quantum Engineering (YINQE), the Yale Chemical and Biophysical Instrumentation Center (CBIC), and the Yale Institute for Yale West Campus Materials Characterization Core (MCC). We appreciate the technical support provided by Dr. Jingbei Liu regarding the confocal magnetron co-sputtering at Yale University. We acknowledge the technical support and helpful discussion provided by Dr. Ying Cao and Dr. Junqi Wang at Yale University regarding the liquid chromatography-mass spectrometry measurement and analysis. We also thank the support received from the National Science Foundation through the Engineering Research Center for Nanotechnology-Enabled Water Treatment (EEC-1449500) and China Scholarship Council (CSC) for providing a graduate fellowship to Y.Z. (grant No. 201806120336).

\section{Author contributions}

Y.Z., M.S., J.M., and M.E. designed the study. Y.Z., M.S., X.W., C.W., W.M., and S.K. performed the experiments. Y.Z., M.S., D.L., and M.E. contributed to the data interpretation. Y.Z., M.S., and M.E. co-wrote the paper. All authors discussed the results.

\section{Competing interests}

The authors declare no competing interests. 


\section{Additional information}

Supplementary information is available for this paper at https://doi.org/10.1038/s41467020-20071-w.

Correspondence and requests for materials should be addressed to M.S. or M.E.

Peer review information Nature Communications thanks the anonymous reviewer(s) for their contribution to the peer review of this work.

Reprints and permission information is available at http://www.nature.com/reprints

Publisher's note Springer Nature remains neutral with regard to jurisdictional claims in published maps and institutional affiliations. (c) (i) Open Access This article is licensed under a Creative Commons Attribution 4.0 International License, which permits use, sharing, adaptation, distribution and reproduction in any medium or format, as long as you give appropriate credit to the original author(s) and the source, provide a link to the Creative Commons license, and indicate if changes were made. The images or other third party material in this article are included in the article's Creative Commons license, unless indicated otherwise in a credit line to the material. If material is not included in the article's Creative Commons license and your intended use is not permitted by statutory regulation or exceeds the permitted use, you will need to obtain permission directly from the copyright holder. To view a copy of this license, visit http://creativecommons.org/licenses/by/4.0/.

(C) The Author(s) 2020 